BULLETIN Bulletin hispanique

HISPANIQUE Université Michel de Montaigne Bordeaux

$115-2$ | 2013

Les traductions vieillissent-elles?

\title{
Què pot voler dir «envellir» quan parlem de traduccions?
}

francesc parcerisas

\section{(2) OpenEdition}

Journals

\section{Electronic version}

URL: http://journals.openedition.org/bulletinhispanique/2646

DOI: 10.4000/bulletinhispanique.2646

ISSN: 1775-3821

\section{Publisher}

Presses universitaires de Bordeaux

\section{Printed version}

Date of publication: 28 December 2013

Number of pages: 451-461

ISBN: 978-2-86781-908-7

ISSN: 0007-4640

\section{Electronic reference}

francesc parcerisas, « Què pot voler dir «envellir» quan parlem de traduccions? », Bulletin hispanique [Online], 115-2 | 2013, Online since 14 February 2017, connection on 03 May 2019. URL : http:// journals.openedition.org/bulletinhispanique/2646; DOI : 10.4000/bulletinhispanique.2646 


\title{
Què pot voler dir «envellir» quan parlem de traduccions? ${ }^{1}$
}

\author{
Francesc Parcerisas \\ Universitat Autònoma de Barcelona
}

La coexistence de traductions anciennes et récentes dans le marché est l'une des caractéristiques les plus remarquables du panorama actuel de la traduction, favorisée, en partie, par le prétexte qu'un nouveau produit surpasse, invalide et délaisse ancien, ce qui n'est pas toujours prouvé.

Mots-clés: retraduction, classiques, politique éditoriale.

La coexistencia de traducciones antiguas y recientes en el mercado es uno de los rasgos más destacables del panorama actual de la traducción, propiciada, en buena parte, por el pretexto que un producto nuevo supera, invalida y arrincona el viejo, lo que no siempre está probado.

Palabras clave: retraducción, clásicos, política editorial.

The coexistence between old and recent translations on the market, is one of the most remarkable characteristics of the current context of translation, favoured, in part, by the pretext that a new product always overcomes, invalidates and puts away the old, which is not always the case.

Keywords: re-translation, classics, editorial policy.

empre m'ha cridat poderosament l'atenció com i quan apliquem
l'adjectiu «vell» a una situació determinada. Des del punt de vista biològic
i demogràfic els joves de 40 anys del segle XXI haurien estat gairebé vells si

1. Aquest article s'inscriu en el Grup d'Estudi de la Traducció Catalana Contemporània (GETCC), 2009, SGR 1294, reconegut i finançat per l'Agència de Gestió i Ajuts Universitaris de la Generalitat de Catalunya, i en el projecte "La traducción en el sistema literario catalán: exilio, género e ideología (1939-2000)», amb el número de referència FFI2010-19851-C02-01, finançat pel Ministerio de Ciencia e Innovación.

Bulletin Hispanique, Tome 115, nº 2 - décembre 2013 - p. 451-461. 
haguessin viscut al segle XVI, i els infants que fa cent anys s'havien de guanyar la vida a deu i dotze anys feinejant als camps de sol a sol o malvivint a les ciutats, avui, a la mateixa edat, són gairebé nadons embolcallats en cotó fluix que es disposen a iniciar l'educació secundària obligatòria. Alguns de vostès potser recordaran una campanya publicitària del 2007 que la fotògrafa americana Annie Leibovitz va fer per a l'empresa Unilever, anunciant els productes de cosmètica Dove's Pro-Age. Les models que emprava la campanya eren dones d'edat, fotografiades despullades, amb totes les seves arrugues, les taques de l'edat, els cabells grisos i una bellesa totalment desacomplexada i extraordinària. La campanya publicitària -a més de voler eixamplar el públic consumidor-ens deia que en aquella bellesa, com en tota bellesa que atorga el pas del temps, hi hem de poder reconéixer, també, una bellesa que ens parla de la veritat de la història.

En aquest sentit no estaria gens malament que tots goséssim fer com el poeta nord-americà Ezra Pound que, a l'inici dels seus Cantos, per referir-se a la primera part del llibre XI de l'Odissea, no ho fa partint d'una versió moderna sinó basant-se en una traducció llatina editada aquí, a París, el 1538. La bellesa de la nèquia homèrica i de l'aparició de l'insepult Èlpenor, deu molt al fet que el poeta tenia al davant una traducció antiga i no pas una versió moderna destinada al gran públic. És possible, doncs, que, en l'afany per multiplicar la velocitat i la banalitat de les experiències culturals, el nostre món s'apressi a bandejar, cada cop més, «la bellesa de la vellesa» $\mathrm{i}$ avui siguin molt pocs aquells que pensin que pot tenir ple sentit -lingüístic i estètic- llegir, per exemple, la Commedia del Dante en la traducció del vigatà Andreu Febrer, acabada a Barcelona l'any 1429, una traducció que, per cert, els lectors actuals encara podem trobar per molts pocs diners a la col-lecció «Els Nostres Clàssics».

Ho podem veure encara en un altre exemple que jo mateix he citat sovint: els anomenats remakes de les pel-lícules en blanc i negre; ¿¿de debò creuen que podem seure impassibles i contemplar a la pantalla Stan Laurel i Oliver Hardy, o Charlot, o Bogart i Bacall, en colors...? Hi ha un cinema que és essencialment en blanc i negre (encara, i em permeto recordar-ho aquí, que el blanc i negre en realitat és la ficcionalització d'un món en color), i que només pot ser autènticament fruït en aquell context de projectors sorollosos, cinemes de barri, i cintes de cellluloïde que es trencaven en els moments més inoportuns. Si per a aquest cinema no volem remakes en colors, per a les novel.les de Georges Simenon traduïdes a l'espanyol a finals dels anys quaranta i primeria dels anys cinquanta per Ferran Canyameres i altres traductors que ell suplantava, en els humils llibrets de butxaca de l'editorial Albor, amb cobertes de Giralt Miracle, jo, com a lector, tampoc no vull noves traduccions que oblidin l'aspecte un xic matusser, afrancesat $i$ alliberador del que era l'essència de la lectura de la sèrie negra a l'Espanya de postguerra.

Faig aquesta introducció perquè considero que l'afany de retraduir, tot i no ser un fet nou, s'ha multiplicat en els temps moderns de manera potser incontrolada i alarmant, en especial a causa dels avenços velocíssims de la tecnologia, sota el supòsit que el producte nou sempre supera, invalida i 
arracona el vell. De manera similar a com diem que els electrodomèstics actuals ja no duren el que duraven els primers i robustos electrodomèstics dels nostres avis, sembla que certs productes del mercat literari, entre ells les traduccions, també estan obligats a envellir a un ritme cada cop més accelerat. Aquest és, doncs, el rerefons del qual parteixen les meves reflexions.

Malgrat tot existeixen diverses raons que justifiquen que una obra literària sigui retraduïda, tot i que potser no són raons lligades ben bé a l'envelliment. Alguns autors han intentat classificar aquestes raons, que podrien dividir-se, bàsicament, en dos grans grups ${ }^{2}$ : raons de tipus diacrònic i raons de tipus sincrònic o, per utilizar la terminologia de G. Toury, «normes preliminars» relacionades amb la política de la traducció $\mathrm{i}$ «normes operatives» centrades en les decisions preses durant el procés de traducció ${ }^{3}$. O, des d'una altra perspectiva classificatòria, podríem parlar de retraduccions «actives» $\mathrm{i}$ "passives», segons la distinció que en fa Anthony $\mathrm{Pym}^{4}$ quan distingeix entre diferències temporals, geogràfiques o dialectals de les retraduccions o retraduccions estrictament contemporànies que competeixen entre elles en un mateix mercat. En qualsevol cas és interessant que aquesta classificació sigui analitzada títol per títol, per tal de poder separar, si cal, retraduccions que ocupen un lloc destacat dins un sistema literari concret (penso en les dues traduccions del 1919 i del 1946 de L'Odissea de Carles Riba) d'altres retraduccions que refan una traducció prèvia considerada "defectuosa», per bé que, si ens hi parem a pensar, en ambdós casos, allò que esperona la nova versió és aparentment la competència (o incompetència) traductora. I, més enllà -i al costat- d'aquestes consideracions, també hauríem de ser capaços de fer veure que les normes preliminars i les normes operatives solen constituir la trama i l'ordit d'una única situació concreta i individual.

Davant el suposat envelliment, la retraducció sempre és una nova creació de valor. I el valor, com coneixen tan bé els especuladors financers, té una dimensió temporal i es troba en constant oscil.lació. Sovint llegim que cal retraduir cada quinze o cada vint-i-cinc anys ${ }^{5}$, però no se'ns donen gaires arguments; potser només l'argument general que, en forma de pregunta, ens convoca avui en aquest col-loqui: que les traduccions envelleixen. L'argument, com a tal, em sembla poc específic, poc detallat. Aquelles senyores «grans» de la campanya publicitària d'Annie Leibovitz ¿han de disfressar la seva edat i sotmetre's a una cirurgia enganyosa? L'exemple espaventós d'una famosa dama de l'aristocràcia

2. Vegeu, per exemple, els articles d'Isabelle Vanderschelden, «Re-translation», dins Olive Classe (ed.), Enciclopaedia of Literary Translation into English, Londres, Fitzroy Dearborn Publishers, 2000, 2 vols., p. 1154-1155, o Joan Fontcuberta, «Retraducciones. El caso Zweig», dins Juan Jesús Zaro Vega i Francisco Ruiz Noguera (eds.), Retraducir. Una nueva mirada, Màlaga, Miguel Gómez Ediciones, 2007, p. 225-231.

3. Gideon Toury, Descriptive Translation Studies and Beyond, Amsterdam / Filadèlfia, John Benjamins, 1995, p. 54-59.

4. Anthony Pym, Method in Translation History, Manchester, St. Jerome Press 1998, p. 82.

5. Vegeu, per exemple, Catherine Argand, «Faut-il tout retraduire?», Lire, febrer 1997. 
espanyola ens hauria de fer pensar en les traduccions antigues que han estat «planxades» per correctors i editors sense escrúpols per tal d'eliminar les belles arrugues d'un «llur» o d'un «en tanta de manera», amb la qual cosa han acabat creant un monstre literari. Solem dir que la traducció és una interpretació i, per tant -de manera semblant a allò que ocorre a la borsa i als mercats- el valor que cada moment atorga a una interpretació determinada, és fluctuant. A partir dels anys vuitanta, els editors francesos van escarrassar-se a retraduir les traduccions que havien envellit o que havien estat esporgades. De la traducció francesa de Moby Dick per Jean Giono es comentava que Giono s'havia saltat tots els passatges de Melville que feien referència a les tècniques marítimes ${ }^{6}$. Quina confusió! En aquest cas, restituir els fragments omesos (que, si em permeten l'incís, no sé si ningú va criticar quan la traducció va aparèixer) no té res a veure amb l'envelliment, i no em sorprendria que la traducció de Jean Giono fos, malgrat els talls, exacta, agradable i tan llegidora com ho eren les seves novel-les.

Isabelle Vanderschelden ha escrit unes paraules amb les que no puc estar més d'acord': «Totes les llengües d'arribada tenen la seva pròpia herència de traduccions de literatura estrangera que són respectades.» Hauríem de poder veure en la història de les traduccions una sèrie de baules que ens parlen dels costums traductològics, dels coneixements, de les tècniques, de l'acceptació per part dels lectors, dels criteris editorials, etc. I tots aquests elements, sumats, ens permetrien, si de cas, bastir un panorama històric de la traducció on l'envelliment en tant que interpretació desfasada hauria deixat, en gran part, d'existir. Vanderschelden parla al seu article del Proust d'Scott Moncrieff, del Montaigne de Florio o del Rabelais d'Urquhart i diu que «són un bon exemple dins la història de la literatura anglesa. I, tanmateix, en qualsevol moment de la seva història -afegeix-, la validesa d'una traducció pot ser qüestionada i això pot dur a una retraducció. Això pot veure's instigat per una sèrie de factors, inclosos els històrics, culturals i intepretatius, però el que acaba apareixent com a tema central de la justificació per a la retraducció és el de la qualitat». La qualitat, ja hi tornem a ser; és a dir: el valor que els deia abans, un valor subjectiu sotmès a les fluctuacions del temps. Víctor Comta (1990), Salvador Oliva (1996) o jo mateix (2010) hem produït en pocs anys tres versions diferents d'Alícia en terra de meravelles, però no gosaria dir que provàvem d'allunyar-nos de manera deliberada de la traducció canònica de Josep Carner (1927), sinó més aviat d'acostar-nos-hi de la manera menys visible perquè Carner, en la literatura catalana, i en la traducció moderna al català, és, malgrat les imperfeccions inqüestionables de la seva "bella vellesa», un referent respectat de la nostra herència.

A partir de la citació de Vanderschelden podríem trobar exemples a bastament en totes les literatures. En el cas català les referències a algunes traduccions "clàssiques» no ha invalidat que se'n tornessin a fer traduccions modernes, i l'excusa de l'envelliment d'aquella qualitat certa, si bé és l'excusa

\footnotetext{
6. Ibid.

7. Isabelle Vanderschelden, «Re-translation», Op. cit.
} 
«interpretativa» que sol aparèixer al davant de tot, no em sembla gens provada. Mirin: la distància temporal podria ser un argument ben lícit en casos com el de les traduccions catalanes de la Commedia de Dante. De la versió de 1429 d'Andreu Febrer a la retraducció de Josep M. de Sagarra (1947, 1949 i 1951) havien transcorregut més de cinc-cents anys, i entre la versió de Sagarra i la de Joan-Francesc Mira (2000) cinquanta. Però jo tindria dubtes seriosos a jutjar en termes de «valor» o de "qualitat» aquestes tres traduccions. No crec que la de Febrer hagi «envellit» tot i que és naturalment «antiga» i requereix una lectura similar a la que ens exigeixen altres títols publicats a la mateixa col-lecció de clàssics catalans antics: un esforç d'atenció que, en ben poc temps, ens proporciona un escreix de gaudi lingüístic.

\section{Si fui gelat e mut, sense dir "hoc» \\ No m'ho demant, lector, que no ho escric, \\ Per ço com tot parlar seria poc.}

(Infern, XXXIV, 22-24)

La traducció de Sagarra és tan rica que qui hagi perdut el gust per la llengua que Sagarra dominava de manera magistral, com pocs altres escriptors de la seva època, la considerarà «envellida», però no crec que, malgrat els seixanta anys transcorreguts, puguem dir que el seu sigui un envelliment que la fa inintel-ligible.

Si vaig quedar gelat i ert com un roc, no ho demanis, lector, que no ho sé escriure, perquè tota paraula fóra poc.

I l'actual traducció de Joan-Francesc Mira, no pel fet de ser contemporània, pot esgrimir solucions més naturals o afortunades que les versions anteriors. (Potser aquesta darrera acabarà envellint més de pressa que les seves antecessores.)

Com de gelat i fluix em vaig quedar, no ho preguntes, lector, que no ho escric perquè no tinc prou paraules per dir-ho.

La cronologia, doncs, pot tenir a veure amb la noció d'envelliment que subjau en tota valoració de les traduccions, però no sempre és el cas. Vegem-ho en un altre exemple.

Les quatre traduccions catalanes de la Bíblia que s'emprenen a principis del segle XX (la del Foment de Pietat Catalana, la de mossèn Clascar, la de la Fundació Bíblica Catalana i la de Montserrat) es distingeixen entre elles per les seves orientacions ideològiques i per la mena de públic ideal a qui anaven destinades, no pas per envelliments cronològics, que no hi eren ni hi podien ser. És més, tant la de Montserrat com la de la Fundació Bíblica Catalana van ser sotmeses a la postguerra a una mena d'aggiornamento, no pas perquè les traduccions que havien iniciat fossin inintel.ligibles, sinó perquè el mercat cultural (i, en concret, religiós) havia canviat i demanava un producte amb un 
embolcall «diferent». Allò que es qüestiona no és en realitat la interpretació de l'original sinó l'encaix de la traducció en la cultura receptora. Sense moure'ns d'aquest exemple dels textos religiosos, voldria mencionar el que pot haver representat, ideològicament, l'aparició, en una col-lecció que bàsicament publica ficció, dels Evangelis (2004) traduïts del mateix Joan-Francesc Mira. En una entrevista al diari El Pais se'n destacava que el traductor s'hi havia acostat sense apriorismes ideològics, com qui tradueix una novel. $\mathrm{la}^{8}$ :

Los textos del Nuevo Testamento traducidos por Mira distan bastante de las traducciones que existen en catalán. Mira ha procurado restituirles su dimensión «narrativa» y depurar al máximo las palabras y expresiones que se han ido cargando de ideología y doctrina. Trata de reproducir cómo debió ser la lectura de un contemporáneo "medianamente culto». Así, por ejemplo, utiliza "alè sagrat» en vez "Espiritu Santo», "esclat» por "Gloria», "culpa» o "error» por "pecado», "exemple» o «comparacio» por "parábola», "despertar-se» o «alçar-se» por «resucitar», "copa» por «cáliz», y «carta» por "epistola». Ha eliminado las notas a pie de página y los títulos y numeración de los versiculos que "sólo están ahi para transmitir más claramente la doctrina y facilitar las citaciones». Resume Mira: "Todo esto condiciona la lectura y yo he querido descondicionarla».

Hi estic totalment d'acord, amb el benentès que sapiguem analitzar el context. Aquesta nova traducció realment ¿restitueix als Evangelis la seva dimensió narrativa? ¿La van tenir mai? Potser vaig equivocat, però jo més aviat creia que els Evangelis eren escrits per fidels d'una secta i que tenien un afany proselitista. La «narrativitat» que ara s'hi subratlla és més una característica del segle XXI que no pas del segle primer. Per tant, cal anar amb compte a l'hora de fomentar allò que és nou només per oposició a allò que és vell.

Entre Un amor de Swan traduït per Jaume Bofill i Ferro a la col-lecció Proa el 1932, i tota la Recerca traduïda per Jaume Vidal Alcover el 1990-1991 hi ha una distància temporal, però hi ha, sobretot (a més de la mostra d'una petita part i de la totalitat de l'obra de Proust), opcions traductores molt diferents, algunes prou discutibles. Com diverses són, sense que hagi transcorregut tant de temps, les opcions que empra la traducció actual de Josep M. Pinto (2009) ${ }^{9}$ iniciada, segons que diu el traductor, no pas per cap sensació d'envelliment de les versions anteriors; en aquest cas, la reivindicació del traductor és la seva lectura de l'original com un text que té una fluència -amb tots els meandres que vulgueu- oral.

El llenguatge de Proust, malgrat la seva reputació de complexitat, és, sobretot, molt col-loquial, la qual cosa no vol dir senzill, tampoc. El vocabulari que utilitza és d'una enorme precisió, però sense artificiositat. Això vol dir que per a aquest volum m’ha tocat recuperar de la meva memòria (gairebé inventariar, tenint en compte la riquesa de l'original) tota una manera de parlar que es va perdent, però que no és arcaica, ni carrinclona, ni artificial, que és ben actual però que s'està perdent, esmussant, davant d'una onada d'uniformització que ve de diversos llocs (televisió, diaris, males

8. Entrevista amb Isabel Obiols El País [Comunidad Valenciana], 15-12-2004.

9. Se n'han publicat dos volums: Combray (2009) i Un amor d'en Swan (2010), Barcelona, El Cercle de Viena. 
traduccions -suposo que és una bola de neu-). Un exemple: que ja no es pugui llegir gairebé en cap traducció el verb «enraonar», el verb «amoïnar», que s'hagi optat per "m'he oblidat de portar-t'ho", tan correcte però al mateix temps tan asèptic, en comptes del més familiar, igualment correcte, però més connectat amb el nervi íntim de la llengua «m’he descuidat de dur-t'ho» ${ }^{10}$.

I ara que parlem de Proust, li podem donar veu un moment en aquest afer, i recordar l'opinió de l'àvia del protagonista, defensora a ultrança de la immarcessibilitat de les traduccions que ella s'havia acostumat a llegir.

Or si une Odyssée d'où étaient absents les noms d'Ulysse et de Minerve n'était plus pour elle l'Odyssée, qu'aurait-elle dit en voyant déjà déformé sur la couverture le titre de ses Mille et une nuits, en ne retrouvant plus, exactement transcrits comme elle avait été de tout temps habituée à les dire, les noms immortellement familiers de Schéhérezade, de Dinarzade, où, débaptisés eux-mêmes, si l'on ose employer le mot pour des contes musulmans, le charmant Calife et les puissants Génies se reconnaissaient à peine, étant appelés l'un le "Khalifat», les autres les "Gennies» ${ }^{11}$ ?

Aquest fragment breu té més suc del que sembla: quan l'imaginari de l'àvia no retroba els noms familiars que s'havia avesat a llegir es produeix un canvi, i els llibres deixen de ser allò que eren. L'envelliment, aquí, vol dir la coneixença, la familiaritat, el retorn a l'espai comú. L'intent de modificar en alguna traducció catalana de Kafka La metamorfosi per La transformació també es va estavellar contra els costums lectors, fins a l'extrem que existeixen edicions en què "la metamorfosi» apareix com a subtítol de la nova traducció La transformación ${ }^{12}$, com si el títol vell pogués encara atorgar una carta de naturalesa prestigiosa al títol nou.

Em sembla que aquesta hibridització, aquesta coexistència en el mercat de traduccions antigues i recents, és un dels trets més destacables del panorama actual de la traducció. Un panorama que, en aquest sentit, no fa altra cosa que sumar-se a les tendències mercantils del nostre món, que intenta oferir als consumidors el màxim de productes sota envoltoris escaients per a cada grup de compradors, encara que els productes mateixos no es distingeixin tant els uns dels altres o que siguin mers genèrics atractivament ensucrats. Primer posaré dos exemples de colleccions en què, en contra del que sembla que pensem, l'envelliment ha estat, de manera explícita, la clau de la promoció de les traduccions.

El primer és una poc coneguda però prou valuosa «Biblioteca de Traductores», que va començar a publicar l'Editorial Júcar de Madrid l'any 1989. La idea d'aquesta col-lecció era enaltir i tornar a posar en circulació antigues traduccions considerades «clàssiques» i que havien desaparegut del mercat. El primer volum

10. Citat a http://joancalsapeu.blogspot.com/2009/09/el-temps-perdut-retrobat-en-catala. html. Consulta: 6-10-2011.

11. Marcel Proust, Sodome et Gomorrhe, París, Gallimard, col. «Folio», 1972, p. 270.

12. Barcelona, Proa, col. «Clàssics Universals», n. 1, 2000. Traducció de Jordi Llovet. La transformación és ara el títol de la versió castellana de Xandru Fernández (Navona, 2009). 
aparegut va ser La Cartuja de Parma, d'Stendhal, en una traducció de Manuel García Morente $^{13}$. A la contracoberta del llibre hi podem llegir:

esta traducción ejemplar de La Cartuja de Parma, preparada con esmero por Manuel García Morente que fue professor de Ética de la Universidad Central y posteriormente decano de la Facultad de Filosofia y Letras, se publicó en 1917. Nunca reimpresa hasta hoy nuestra edición es, al mismo tiempo, un rescate y un importante acontecimiento cultural.

La veritat és que tampoc no hi ha una explicació "traductològica» de les bondats de la traducció de García Morente, però a la introducció al llibre, Francisco López escriu: «[Morente] supo ser, a nuestro juicio, un fiel intérprete del texto stendhaliano» (p. 13). Tanmateix jo no hi he trobat cap altre argument que justifiqui l'elecció d'aquesta traducció per damunt d'unes altres dues més antigues, la de L. de Montemar, de 1899, i una altra de Gregorio Lafuerza, de 1914. Per tant no es tracta només d'antiguitat, sinó d'alguna qualitat -d'algun valor, com he dit abans- no explicada que ha perviscut al llarg del temps. Aquí podríem fer un símil musical: no n'hi ha prou amb tocar amb instruments d'època, cal que els instruments d'època siguin bons. Sembla que el prestigi de la traducció canònica permetia que l'edició entrés al mercat en competència amb dues traduccions més recents ben posicionades en el sistema literari espanyol: la traducció de La Cartuja de Parma (1964) del professor Antonio Vilanova i la de Consuelo Berges (1978), una de les traductores més prestigioses de literatura francesa. Caldria fer una recerca de les edicions d'aquestes tres traduccions els darrers vint-i-cinc anys per veure si el prestigi i la respectada antiguitat de la de García Morente van afavorir-ne o no la circulació.

L'altre cas que vull comentar podria anomenar-se alguna cosa com «la tradició de la supremacia». Em refereixo ara a la col-lecció de l'editorial italiana Einaudi «Scritttori Tradotti da Scrittoti», una sèrie iniciada els anys vuitanta $\mathrm{i}$ que continuava vigent a finals dels anys noranta. La sèrie duia publicats uns seixanta títols que anaven des d'Apuleu, Ėsquil, Petroni i Shakespeare a Voltaire, Flaubert, E.A. Poe, J. Conrad, H. Melville, Molière, Dickens o modernistes com Faulkner, Joyce, Gide, Valéry, V. Woolf o S. Beckett. La col-lecció publica el text original acompanyat d'una traducció italiana signada per un escriptor de prestigi reconegut $\mathrm{i}$, de vegades, per una altra traducció, considerada també modèlica, en una altra llengua. A més els llibres porten prefacis i notes. Un bon exemple és la novel.la de Joseph Conrad Thyphoon ${ }^{14}$, que va acompanyada d'una segona traducció, la francesa d'André Gide. L'assaig final analitza, en aquest cas, la traducció de Gide i no la italiana. El criteri d'aquesta sèrie expressat pels editors fa així:

13. Stendhal, La cartuja de Parma, traducció de Manuel García Morente, edició de Francisco López, Madrid, Editorial Júcar, col. «Biblioteca de Traductores», n. 1, 1989, 519 p.

14. Typhoon di Joseph Conrad nella traduzione di André Gide. Versió italiana d'Ugo Mursia, a cura de Valerio Magrelli, Torí, Einaudi, «Scrittori Tradotti da Scrittori», n. 50, 1993, 379 p. A la mateixa sèrie Humpty Dumpty de Lewis Carroll (Einaudi, 1993) duu la traducció francesa d'Antonin Artaud costat per costat de la traducció italiana de Guido Almansa i Giuliana Pozzo amb el text anglès i francès acarats i la traducció italiana a peu de pàgina, mentre que les notes són distribuïdes de manera equilibrada al peu, tant de les pàgines parells com de les senars. 
Sempre più spesso, al cinema come all'opera, lo spettatore si trova ad affrontare il nastro alfabetico dei sottotitoli. Per quanto improprio, l'esempio dà un'idea della scommessa che l'Einaudi lancia con la serie internazionale della collana Sts (Scrittori Tradotti da Scrittori). L'iniziativa presenta infatti i casi più significativi di traduzione tra due lingue straniere, invitando il lettore a seguirli, parola per parola, sulla base di una versione italiana. Testi brevi, cruciali, basati sull'incontro fra alcuni dei massimi interpreti della storia letteraria nel ruolo di tradotto o traduttore. Davanti a questo triplice reticolato, la nota del curatore farà da guida a un inconsueto viaggio intertestuale, itinerario tra culture diverse e insieme perlustrazione dei più segreti nuclei generativi della scrittura. Malgrado qualche raro precedente, la compresenza di tre lingue costituisce una novità editoriale assoluta, e certo, sulle prime, potrà disorientare. Se già il tradizionale testo a fronte costringe lo sguardo a una sorta di «effetto tennis», cosa accadrà con tre campi visivi? La soluzione risulta più semplice di quanto non sembri: padroneggiare questo schema tipografico, come succede con i sottotitoli, è solo una questione di abitudine. Si tratterà di superare i consueti automatismi di lettura, ma la fatica verrà ampiamente ricompensata. Quale migliore occasione per penetrare nel laboratorio di un'opera, studiare una lingua, o seguire da vicino l'atto del tradurre.

In tempi di pesante omologazione culturale, sotto la crescente minaccia di uno speranto planetario, questa «sfida» vuole esaltare la pluralità delle lingue, riportando l'attenzione sul carattere più proprio e specifico del fare letterario.

Paga la pena de subratllar frases tan significatives com «casi piú significativi di traduzione tra due lingue straniere, invitando il lettore a seguirli, parola per parola, sulla base di una versione italiana» que ens recorda aquells llibres antics per estudiar llatí amb les traduccions interliniars, o les edicions clàssiques de la Bíblia amb els textos en hebreu, grec i llatí, al costat de la traducció a la llengua «vulgar», tot en la mateixa pàgina. A més a més allò que la col-lecció proposa no són textos menors o sense transcendència sinó exemples crucials «dei massimi interpreti della storia letteraria nel ruolo di tradotto o traduttore». El fet que original i traducció hi apareguin costat per costat i tinguin la mateixa consideració tampoc no és un acte de cultura innocent o irrellevant. Menys encara si ens fixem en la frase que apareix a la publicitat d'Einaudi:

In tempi de pesante omologazione culturale, sotto la crescente minaccia di un speranto planetario, questa "sfida" vuole essaltare la pluralità delle lingue, ripportando l'atenzione sul carattere piú propio e speficico del fare letterario.

Allò que ens hi juguem -sembla dir-nos aquesta col-lecció- és la pluralitat mateixa de llengües, l'essència, per tant, de la traducció. En la novel-la de Conrad Tifó cal destacar que la traducció d'André Gide és la que ocupa el lloc més destacat ja que allò que importa és «la qualità del testo de arrivo piú che la fedeltà all'originale [ja que] lo scrittore cercò dunque di trasfondere nel suo francese il poderoso flusso narrativo dell'inglese» (p. 364), fins a tal punt, que una mica més endavant en aquest llibret se'ns informa que la traducció de Gide va ser en el seu moment anunciada com "Le plus beau roman de Conrad / La plus belle traduction de Gide» fins a tal punt que "Monod [...], dirigendo le opere complete di Conrad presso la Pléiade, ha deciso di riproporre la versione gidiana senza alcuna revisione. In base a questo eccezionale trattamento, il testo viene presentato come "une ceuvre dont bien des traducteurs plus compétents en théorie pourraient envier 
la qualité littéraire et la vie indépendante» (p. 371). M'he detingut una mica en aquest exemple, perquè s'hi posa de manifest que l'envelliment ben tractat d'una traducció en pot esdevenir un motiu de canonització.

Aquest tractament canònic, emperò, també té desavantatges. Acostuma a formar una mena de «tap» que manté viva en el mercat la vella traducció, a la qual costa de desplaçar amb traduccions noves que li puguin fer la competència. Aquest exemple sovint el trobem en el cas dels textos clàssics grecollatins: les sèries de traduccions de les editorials acadèmiques es reimprimeixen un cop i un altre, mentre que traduccions més «noves» han de lluitar per obrir-se camí en el mercat. El resultat sol ser una duplicitat de traduccions dirigides a mercats diferents: la traducció canònica anotada i acompanyada amb un estudi va al mercat especialitzat, i les noves traduccions omplen diferents funcions de divulgació en col-leccions diverses. Només de tant en tant, una nova traducció acadèmica apareix i suplanta l'antiga i esdevé canònica ella mateixa, però aquest fenomen només sol donar-se dins una mena de cercle especialitzat, en què la nova traducció canònica té lligams estrets de filiació amb l'antiga a la qual suplanta.

Aquests «taps» creats per traduccions canòniques -amb les quals esdevé inevitable de comparar tot intent de traducció nova- solen acabar formant part integral del sistema literari de la llengua d'arribada (tot i que encara són raríssimes les històries de les literatures nacionals que així ho reconeixen). Les traduccions d'Edgar Allan Poe fetes per Baudelaire, les traduccions espanyoles de Julio Cortázar, el Rilke català de Joan Vinyoli, les traduccions de novel.la americana a l'italià fetes per Cesare Pavese... La llista, si ens hi posem a pensar, seria, per sort, força llarga. Diríem que, en aquests casos, l'obra original es troba tan ben servida per la traducció canònica que, com passava en el Gide que he mencionat, o com en l'Orlando de Virgina Woolf traduït a l'espanyol per Borges, passen a ser de ple dret obres del traductor. En català també parlem sovint de L'Odissea de Riba, de la poesia xinesa de Marià Manent, de les Faules de Lafontaine de Benguerel... i atorguem a les velles traduccions un estatus que les allunya de ser comparades o bandejades.

El paradigma d'aquesta superposició - gairebé foixiana- de vell i nou és el catàleg de la col-lecció Penguin Classics. Al catàleg de l'any 1997, per exemple, trobem, costat per costat tres volums de traduccions angleses de la Divina Comèdia en dues traduccions diferents: la de Dorothy Sayers i la de Mark Musa. També hi trobem quatre traduccions diferents de The Iliad, dues en vers (la versió barroca d'Alexander Pope al costat de la versió moderna de Robert Fagles) i dues més en prosa (la de Émile Victor -primer director literari dels Penguin Classics- i una altra versió moderna en prosa signada per Martin Hammond). $\mathrm{Si}$ totes aquestes traduccions coexisteixen en el mateix catàleg, ¿podem pensar que és perquè les velles traduccions han estat desbancades per les traduccions més recents? I, si no és així, ¡com és que les traduccions «velles», que ja no estan de moda, no han desaparegut del catàleg? Davant el suposat perill de l'envelliment, les estratègies del mercat han trobat una manera de satisfer la diversitat de la demanda amb una diversitat de productes. Les traduccions han 
esdevingut productes en el mercat cultural, no gens diferents dels brics de llet o dels iogurts que trobem a les prestatgeries dels nostres supermercats: sencera, semidesnatada, desnatada, amb sucre, sense, etc.).

Acabaré tornant a la pregunta inicial d'aquesta intervenció: «¿Què pot voler dir "envellir" quan parlem de traduccions?». Doncs segurament vol dir que, des d'un cert àmbit crític (dels lectors, dels editors, dels traductors...), la traducció analitzada no reuneix els valors que són moneda de canvi comuna del moment. Però en realitat aquesta mena de judicis de valors ens diuen més sobre els judicants o judicataires que no pas sobre la cosa jutjada, en aquest cas sobre la traducció en qüestió. Si féssim l'esforç de centrar-nos en l'anàlisi de les traduccions hauríem d'acabar creant una mena d' "ontologia temporal» que abracés diferentment les sèries de textos traduïts i els seus originals. I segurament aquesta ontologia ens revelaria algunes falòrnies que no obeeixen a cap raó científica, sinó a interessos o prejudicis injustificats. Si els francesos del segle XXI encara són capaços de llegir Proust (ho són, oi?), ¿no poden els anglesos continuar llegint la traducció d'Scott-Montcrieff? ¿Si els espanyols poden llegir les dues parts del Quixot (1605-1615) només modernitzant-ne l'ortografia, com és que els anglesos no poden llegir les dues parts de la traducció (1612-1620) de Thomas Shelton, que són estrictament contemporànies, tot i que no semblen massa empegueïts a l'hora de llegir The King James Bible que és del 1611? De ben segur que hi ha catalans que poden llegir les edicions originals de Dickens, Baudelaire o Tolstoi, en anglès, francès o rus però ¿ no poden llegir les versions catalanes d'aquests autors que es van publicar a la Catalunya de preguerra?, ¿vol dir això que el català ha «envellit pitjor» que les llengües originals? ¿Alguns voldrien que existissin llengües que, de tan fortes i ben conservades, sempre fessin goig, mentre que d'altres, als dos dies, ja fossin «llengües pansides»? A mi no em fa res llegir les traduccions de Cansinos Assens, de Zenobia Camprubí, de Gide o de Giono, però també vull poder llegir -i d'habitud ho faig no només sense engavanyar-me sinó amb la fruïció d'aprendre-hi moltes coses- les traduccions de Carner, de Nin, de Riba, de Tasis, de Xuriguera, de Manent. No em sembla acceptable afirmar que les traduccions de Faulkner, de Steinbeck o de Dos Passos hagin envellit més de pressa que l'estil dels seus autors, com de vegades semblen suggerir les noves traduccions amb què els editors inunden el mercat. Que moltes d'aquestes traduccions antigues tenen arrugues, i tant! Però són unes arrugues, com ho és el cine en blanc i negre, que per a mi sempre continuaran guardant el secret de tota la bellesa enorme de la història de la traducció. 